\title{
Math Mindsets and Academic Grit: How Are They Related to Primary Math Achievement?
}

\author{
Sibel Kaya ${ }^{1 *}$ \\ (D) 0000-0001-8417-3627
}

\section{Dilan Karakoc ${ }^{1}$}

(D) 0000-0002-3717-6064

${ }^{1}$ Department of Primary Education, Kocaeli University, TURKEY

*Corresponding author: sibel.kaya@kocaeli.edu.tr

Citation: Kaya, S., \& Karakoc, D. (2022). Math Mindsets and Academic Grit: How Are They Related to Primary Math Achievement?. European Journal of Science and Mathematics Education, 10(3), 298-309. https://doi.org/10.30935/scimath/11881

\section{ARTICLE INFO}

Received: 4 Jan 2022

Accepted: 3 Mar 2022

\begin{abstract}
In recent years, Dweck (2014) and Duckworth (2016) introduced two important concepts in student learning: mindsets and grit. These variables can drastically change the way individuals handle a learning situation, the degree of effort and persistence they display, and eventually, their level of achievement. Recent literature on self-theories recommends using domain-specific rather than domain-general instruments to explain school achievement. Furthermore, child samples are relatively understudied compared to adolescent and youth samples in terms of selftheories and achievement relations. This study focuses on math mindsets, academic grit, and their relation to math achievement at the primary school level. Math mindsets scale, academic grit scale, and a math achievement test were used as data collection instruments. Data were collected from purposively selected $2254^{\text {th }}$ grade students in Istanbul, Turkey. A cross-sectional causal model has been tested through structural equation modeling (SEM). There was not a direct effect of growth math mindset but a significant negative effect of fixed math mindset on math achievement. The indirect effect of growth math mindset on math achievement mediated by academic grit was positive and significant; the indirect effect of fixed math mindset was nonsignificant. Finally, the effect of academic grit on math achievement was positive and significant. The SEM model explained $36 \%$ of the variance in math achievement and $64 \%$ of academic grit. School-based interventions are recommended to promote a growth math mindset and academic grit. Practical and theoretical implications are discussed in detail.
\end{abstract}

Keywords: growth mindset, fixed mindset, academic grit, math achievement, primary students

\section{INTRODUCTION}

Research on self-theories in education has gained momentum in recent years. One of the commonly studied self-theory has been mindsets. They were proposed by Dweck $(1999,2006)$ regarding the malleability of individual's qualities such as intelligence and personality. Dweck (1999) suggests that these non-cognitive variables can drastically change the way individuals handle a learning situation, the degree of effort and persistence they display, and eventually their level of achievement. Another self-theory that caught the attention of researchers and policymakers is grit. Grit is related to performance and retention in school and the workplace (Duckworth et al., 2007; Duckworth \& Quinn, 2009). Duckworth (2016) argued that grit is also changeable and malleable therefore has great potential to facilitate development and success. Both Dweck's (2014) and Duckworth's (2016) conceptualization of mindset and grit were domain-general, meaning they apply to all fields, from school to workplace. However, in recent years, especially for school learning, domainspecific mindset and academic grit measures are recommended by researchers (Clark \& Malecki, 2019; Costa \& Faria, 2018; Lou \& Noels, 2019). Therefore, this study focuses on domain-specific mindsets and academic

Copyright (C 2022 by authors; licensee EJSME by Bastas, CY. This article is an open access article distributed under the terms and conditions of the Creative Commons Attribution License (http://creativecommons.org/licenses/by/4.0/). 
grit concerning achievement. Namely, the interplay among math mindsets, academic grit, and math achievement has been investigated.

\section{Math Mindsets}

According to Dweck (1999), there are some adaptive and maladaptive cognitive-motivational dispositions in learning. These dispositions form people's self-theories, and they have influences on achievement and wellbeing. An important aspect of these self-theories is how people approach intelligence. Dweck $(1999,2006)$ and Dweck and Yeager (2019) helped build the concept of theories of intelligence, also known as mindsets, as a powerful psychological construct. Mindsets are based on two basic assumptions that people maintain about their intelligent capabilities: while some think that intellectual abilities are unchangeable (fixed mindset), others believe that their capabilities can be improved through practice and instruction (growth mindset) (Dweck, 1999).

According to the mindset theory, having a growth mindset positively affects academic success, whereas a fixed mindset predicts achievement negatively (Cury et al., 2006; Gouëdard, 2021; Yuksel et al., 2021). This relationship can be a direct one (e.g., Bostwick et al., 2017; Claro et al., 2016; Muller \& Dweck, 1998; Zhao \& Wang, 2014) or can be mediated by some other psychological constructs such as beliefs about effort and strategies for self-regulation (e.g., Blackwell et al., 2007; Müllensiefen et al., 2015). Two recent meta-analyses on mindsets revealed a weak (Costa \& Faria, 2018; Sisk et al., 2018) relationship between mindsets and achievement. It is argued that mindsets tend to be domain-specific that mindsets about specific domains exist independently of each other (Ryan \& Mercer, 2012). In other words, a person can hold a growth mindset in one field but a fixed mindset in another (Dweck et al., 1995). Therefore, recent research on mindsets argues that some domain-specific inventories can provide new insights into examining this construct (Boyd \& Ash, 2018; Costa \& Faria, 2018; Lou \& Noels, 2019).

Similar to general intelligence, math mindsets are based on two assumptions about math intelligence: people either think they have a 'fixed math mindset' in which their capability to accomplish a given mathrelated task is innate and fixed or a 'growth math mindset' in which their capability about math can be developed with practice or instruction (Daly et al., 2019). Previous research has found that students' growth math mindset was associated with gains in their math outcomes at the secondary school level (Bostwick et al., 2017, 2019). Studies that used a general growth mindset also found positive associations with math achievement. With a large sample of Chilean high school students, Claro et al. (2016) found that a growth mindset was a strong predictor of math achievement. Similarly, in Romero et al. (2014) reported that middle school students who endorse a growth mindset earned higher grades and were more likely to choose advanced math courses over time. In a recent study, Bernardo (2020) found that a growth mindset was positively associated with math achievement in PISA 2018 only among the higher SES students.

On the other hand, holding a fixed mindset about math learning has been shown to lead to weaker attainment outcomes for middle and high school students (Blackwell et al., 2007; Hwang et al., 2019). A fixed mindset about general intelligence too, negatively influences math scores of junior high students (Zhao \& Wang, 2014). Research on mindset-math achievement relationships focuses mainly on adult and adolescent populations. This relationship needs further elucidation for child samples. The current study aims to advance the understanding of mindset effects on math achievement in a primary school sample.

\section{Academic Grit}

Grit has been introduced by Duckworth et al. (2007) and Duckworth and Quinn (2009) as a personality trait that predicts achievement. It has two aspects, namely consistency of interests and perseverance of effort. Consistency of interests refers to not changing goals and interests frequently; and perseverance of effort implies the predisposition to work hard even in the face of obstacles. Both aspects are assumed to contribute to the success (Duckworh \& Quinn, 2009). Duckworth et al. (2007) argue that grit can be a better indicator of success than the ability test scores. In their meta-analysis, Credé et al. (2017) found that grit was moderately correlated with success. However, it was highly correlated with conscientiousness.

Several studies have found a positive association between grit and academic achievement at the university level (e.g., Duckworth et al., 2007; Strayhorn, 2014; Wolters \& Hussain, 2015). With adolescent students, grit was positively associated with GPA (Duckworth \& Quinn, 2009; Dumfart \& Neubauer, 2016; Guerrero et al., 


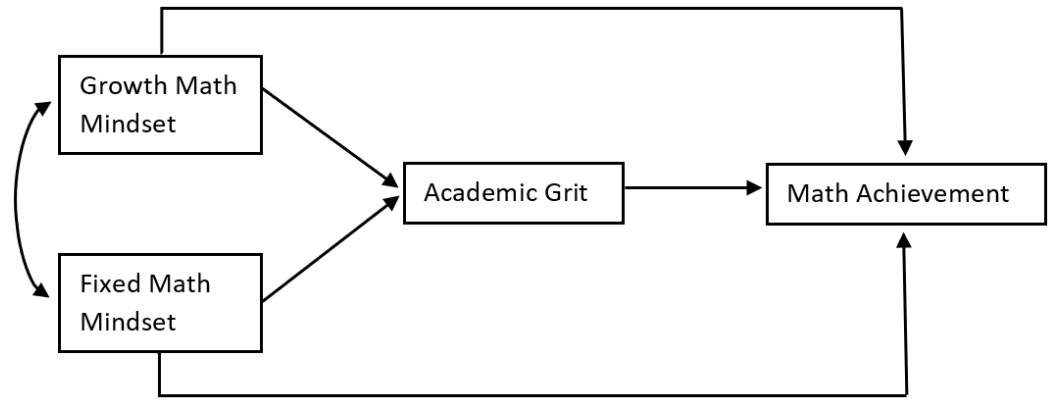

Figure 1. The proposed model of math mindsets, academic grit, and math achievement relationships

2016) and achievement tests (Al-Mutawah \& Fateel, 2018; Cosgrove et al., 2018; West et al., 2016). Among very few studies that included primary school age groups, Tucker-Drob et al. (2016) found a significant association between grit and performance on a standardized math and reading test. Grit was also related to several noncognitive attributes. For example, Sigmundsson et al. (2020) found a significant relationship between grit and growth mindset in Icelandic college students. Similarly, Kannangara et al. (2018) reported that grittier college students showed higher levels of growth mindset, resilience, mental well-being, and self-control. In a primary school sample, grit was significantly related to academic-self efficacy and school satisfaction (Oriol et al., 2017).

In recent years, psychometric properties of the grit scale, developed by Duckworth and Quinn (2009), have been scrutinized, and a recent meta-analysis study by Credé et al. (2017) recommended a reconceptualization of grit. Some studies reported low levels of psychometric properties (e.g., Al-Mutawah \& Fateel, 2018; Datu et al., 2016; Guerrero et al., 2016; West et al., 2016), and some studies demonstrated greater criterion-related validity for perseverance of effort than consistency of interests (e.g., Akos \& Kretchmar, 2017; Bowman et al., 2015; Datu et al., 2016; Dixson et al., 2016; Wolters \& Hussain, 2015). For college students, perseverance of effort was more strongly correlated with achievement than consistency of interests when analyzed separately (e.g., Akos \& Kretchmar, 2017; Bowman et al., 2015; Wolters \& Hussain, 2015). In several studies that examined adolescents' outcomes, consistency of interests failed to predict adolescent outcomes whereas perseverance of effort predicted them significantly (Bowman et al., 2015; Datu et al., 2016; Dixson et al., 2016; Tang et al., 2019), which indicated a single factor structure for grit rather than two.

Another criticism of Duckworth's grit scale (Duckworth et al., 2007; Duckworth \& Quinn, 2009) was its domain-general nature. Researchers argue that effort and interest may vary in different aspects of life, such as school or hobbies. Therefore, domain-specific grit scales are needed to explain school achievement (Clark \& Malecki, 2019; Schmidt et al., 2019). Schmidt et al. (2019) converted the domain-general grit scale items into school-specific items. They found that school-specific grit was more closely related to German college students' GPA than domain-general grit (Schmidt et al., 2019). With similar concerns in mind, Clark and Malecki (2019) developed the Academic grit scale with 10 items that constitute a single factor. Academic grit was positively related to academic achievement and school satisfaction. Furthermore, academic grit explained more in academic achievement and school satisfaction than did general grit. Clark and Malecki (2019) recommended the elucidation of the predictive power of academic grit with children and adults, also in specific content areas (e.g., math). Researchers also suggest that academic grit can be a mediator between perceptions and beliefs related to schoolwork and school achievement. The current study aims to investigate this mediating effect.

The current study aims to investigate the relationships among math mindsets, academic grit, and math achievement of primary school students. Figure 1 shows the proposed model of these relationships. Previous research highlighted direct effects of math mindsets (e.g., Bostwick et al., 2017, 2019; Daly et al., 2019) and academic grit (e.g., Clark \& Malecki, 2019; Schmidt et al., 2019) on achievement. Some studies showed that the effects of mindsets have been mediated by other psychological constructs (e.g., Blackwell et al., 2007; Müllensiefen et al., 2015). Both Dweck (1999) and Duckworth (2016) emphasized the importance of a growth mindset to develop grit; in other words, individuals with a growth mindset tend to be grittier. Furthermore, several studies found a moderate positive association between growth mindset and general grit (e.g., Blackwell et al., 2007; Burgoyne et al., 2018; Kannangara et al., 2018; Zhao et al., 2018). Considering all these associations, we used academic grit as the mediating factor between math mindsets and math achievement. 
We propose that there is a positive direct effect of growth math mindset and a negative direct effect of fixed math mindset on math achievement. Furthermore, there is a positive indirect effect of growth math mindset and a negative indirect effect of fixed math mindset on math achievement mediated by academic grit. Finally, there is a positive effect of academic grit on math achievement. Eventually, this study seeks to answer the following research questions:

1. What are the direct effects of growth math mindset and fixed math mindset on math achievement?

2. What are the indirect effects of growth math mindset and fixed math mindset on math achievement mediated by academic grit?

3. What is the effect of academic grit on math achievement?

\section{METHOD}

\section{Sample}

Data were collected from $2254^{\text {th }}$ grade students in 7 classrooms. $4^{\text {th }}$ grade is the final year in primary schooling in Turkey. Since the comprehension level is higher at this grade compared to earlier grades and the released Trends in International Mathematics and Science Study (TIMSS) items that are used to measure math achievement are more appropriate for $4^{\text {th }}$ grade, this grade level has been preferred. Therefore, a purposive sampling method was used. For structural equation modeling analysis, a sample size larger than 200 is considered adequate (Kyriazos, 2018). There were 118 females and 107 males with an average age of 10. The school from which data were collected is an urban school in Istanbul, Turkey; and admits students mainly from families of low to medium SES. The average class size for $4^{\text {th }}$ grade classrooms was 32 . Since the second author of this paper was a teacher at this school the accuracy for data collection was high; however, results may not be generalizable to other populations since only one school participated in the study.

\section{Data Collection}

Data were collected in two weeks during the Spring of 2021. The second author was present in the classrooms during the administration of instruments, and she assisted when needed. In all classes, a math test compiled from the released (TIMSS) items was administered first. The math mindsets scale and academic grit scale were administered in a separate class session. Students completed the math test in 35-40 minutes, and the other instruments took approximately 10 minutes to complete.

\section{Data Sources}

\section{Math mindsets scale}

The general mindsets scale was developed by Dweck (1999) and consisted of six items in a 6-point Likert format, from 'strongly disagree' to 'strongly agree'. Of these items, three of them represent a growth mindset, and the other three represent a fixed mindset. A growth mindset argues that intellectual capabilities can be improved through hard work whereas, a fixed mindset argues that intellectual capabilities are unchanged no matter how hard a person tries. There are two separate scores that this scale yields: one for a growth mindset and the other is for a fixed mindset. The scale was adapted into Turkish by Beyaztas and Hymer (2018), and the Cronbach's alpha reliability scores for growth and fixed mindset have been found as $a=0.81$ and $a=0.70$, respectively.

In recent years to better explain school success, the need for domain-specific mindset scales has been highlighted (Boyd \& Ash, 2018; Costa \& Faria, 2018; Lou \& Noels, 2019). Hence, by simply adding the domain name to Dweck's (2006) original general mindset items, domain-specific mindset scales have been developed (i. e., Degol et al., 2018; Hwang et al., 2019). For example, a growth math mindset item can be: No matter who you are, you can change your math intelligence a lot; a fixed math mindset can be: You have a certain amount of math intelligence, and you really cannot do much to change it. Confirmatory factor analysis with 6 items indicated a good fit for the 2-factor model $(C F I=0.99, T L I=0.98, R M S E A=0.09, S R M R=0.035)$. Cronbach's alpha reliability coefficient was computed as $\mathrm{a}=0.92$ for growth math mindset and $\mathrm{a}=0.94$ for fixed math mindset. Three of the six items measured fixed math mindset and a higher score indicates a stronger disposition towards the belief that math intelligence is fixed and cannot be improved through hard work. The other three items 
measured growth math mindset and a higher score indicates a stronger disposition towards the belief that math intelligence can be improved through hard work and practice. All items were positively coded.

\section{Academic grit scale}

The 10-item academic grit scale has been developed by Clark and Malecki (2019). Clark and Malecki (2019) decided to develop this scale since the short grit scale, originally developed by Duckworth and Quinn (2009), yields low reliability and may not be appropriate for explaining school-related outcomes. The scale has ten 5point Likert-type items, 1 being 'not at all like me' and 5 being 'very much like me'. The academic grit scale was translated to Turkish by two language specialists with PhD. The Turkish version of the scale was then backtranslated into English and checked by the researchers for any differences. The scale was pilot-tested on 33 $4^{\text {th }}$ grade students who shared similar socio-economic backgrounds with the actual study group. Students reported no difficulty or confusion in understanding the items. Then the scale has been administered to the actual study group. Confirmatory factor analysis with 10 items indicated a good fit for the 1-factor model $(\mathrm{CFI}=0.99, \mathrm{TLI}=0.97, \mathrm{RMSEA}=0.08$, and $\mathrm{SRMR}=0.04)$. The final version of the academic grit scale was administered together with the math mindset scale. Cronbach's alpha reliability coefficient was computed as $\mathrm{a}=0.96$. The scale included items such as I push myself to do my personal best in school; and even when I could do something more fun, I give schoolwork my best effort. A higher score on the academic grit scale indicated a higher school-related grit and all items were positively coded.

\section{Math achievement test}

The math achievement test was compiled from the released items of previous TIMSS assessments. There were 20 questions in the test, and each question was worth 1 point. Therefore, the maximum possible score on the test was 20. The original TIMSS test is composed of three cognitive domains: knowing, applying, and reasoning. Knowing covers the facts, procedures students need to know, and routine problems; applying focuses on the ability of students to apply their knowledge to solve problems, and reasoning involves solving unfamiliar, non-routine problems with complex contexts and multiple steps. Reasoning questions comprise approximately $20 \%$ of questions while knowing and applying comprise $40 \%$ each in the $4^{\text {th }}$ grade assessment. In terms of content, nearly half of the questions are related to numbers; $30 \%$ is related to measurement and geometry, and $20 \%$ is about data at the $4^{\text {th }}$ grade level (Mullis \& Martin, 2017). We paid attention to keeping this structure and the ratio of each cognitive and content domains. In terms of question format, similar to the original assessment, 12 items were in multiple-choice format, and eight items were open-ended. For the reliability of multiple-choice items, the KR-20 coefficient was calculated as 0.76 for 12 multiple-choice items with an average item difficulty of 0.41 . These coefficients are considered adequate for a reliable test (Fraenkel \& Wallen, 2008). For the reliability of open-ended items, two researchers graded the students' tests independently, and any disagreements have been negotiated.

\section{Data Analysis}

Descriptive statistics for math mindsets, academic grit, and math achievement were computed; and skewness and kurtosis values were used to check normality. To examine the relationships among these three constructs, structural equation modelling (SEM) was conducted in the R program. Our purpose was to examine the direct effects of math mindsets and academic grit as well as the indirect effects of growth and fixed math mindsets on math achievement. SEM enables us to investigate the structural relationships among observed variables and latent constructs by estimating confirmatory factor analysis, linear regression, and path relations (Byrne, 2016). In order to evaluate the model, we utilized the cut-off values suggested by Hair et al. (2014) and Kline (2016) as CFI>0.90, TLI>0.90, RMSEA $<0.10$, and SRMR<0.08 as an acceptable fit.

\section{RESULTS}

According to the descriptive analysis results (Table 1), growth and fixed math mindset scores ranged between three and 18 with average scores of $11.16(S D=4.78)$ and $10.50(S D=5.21)$, respectively. Academic grit scores ranged between 10 and 50, with an average score of $34.16(S D=11.25)$. As for math achievement, the minimum score was 1, the maximum score was 19, and the mean score was $8.44(\mathrm{SD}=4.91)$. Even though the maximum available score was 20 on the math test, no student received a perfect score. The skewness and 
Table 1. Descriptive statistics of math mindsets, academic grit, and math achievement

\begin{tabular}{lcccccc}
\hline & Min & Max & Mean & SD & Skewness & Kurtosis \\
\hline Growth math mindset & 3 & 18 & 11.16 & 4.78 & -0.18 & -1.38 \\
Fixed math mindset & 3 & 18 & 10.50 & 5.21 & 0.01 & -1.50 \\
Academic grit & 10 & 50 & 34.16 & 11.25 & -0.21 & -1.13 \\
Math achievement & 1 & 19 & 8.44 & 4.91 & 0.27 & -1.11 \\
\hline
\end{tabular}

Table 2. Correlations among math mindsets, academic grit, and math achievement

\begin{tabular}{lcccc}
\hline & Growth math mindset & Fixed math mindset & Academic grit & Math achievement \\
\hline Growth math mindset & 1 & $-0.649^{* *}$ & $0.564^{* *}$ & $0.562^{* *}$ \\
Fixed math mindset & & 1 & $-0.397^{* *}$ & $-0.484^{* *}$ \\
Academic grit & & 1 & $0.765^{* *}$ \\
Math achievement & & & 1 \\
\hline
\end{tabular}

Note. ${ }^{* *} p<0.01$

Table 3. SEM results of the relations among math mindsets, academic grit, and math achievement

\begin{tabular}{lcc}
\hline & $\beta$ & SE \\
\hline Direct effects & & 0.223 \\
Growth math mindset $\rightarrow$ Math achievement & 0.073 & 0.237 \\
Fixed math mindset $\rightarrow$ Math achievement & $-0.170^{\star *}$ & 0.271 \\
Academic grit $\rightarrow$ Math achievement & $0.662^{\star *}$ & 0.115 \\
Growth math mindset $\rightarrow$ Academic grit & $0.593^{* *}$ & 0.128 \\
Fixed math mindset $\rightarrow$ Academic grit & -0.008 & 0.139 \\
Growth math mindset $\rightarrow$ Fixed math mindset & $-0.681^{\star *}$ & 0.282 \\
Indirect effects & & 0.333 \\
Growth math mindset $\rightarrow$ Academic grit $\rightarrow$ Math achievement & $0.393^{* *}$ & -0.005 \\
Fixed math mindset $\rightarrow$ Academic grit $\rightarrow$ Math achievement & CFI=0.99, TLI=0.99, RMSEA $=0.068$, SRMR $=0.026$ \\
Model fit indices
\end{tabular}

Note. ${ }^{* \star} \mathrm{p}<0.01$; For math achievement $\mathrm{R}^{2}=0.36$; For academic grit $\mathrm{R}^{2}=0.64$

kurtosis scores were between -1.5 and 1.5; therefore, they are considered to be normally distributed, which is the requirement for using parametric data analysis methods (Tabachnick \& Fidell, 2007).

Table 2 displays the correlations among math mindsets, academic grit, and math achievement. Accordingly, there was a high positive correlation between academic grit and math achievement $(r=0.765$; $p<0.01$ ). As for the correlations between math mindsets and math achievement, they were moderate. Growth math mindset was positively $(r=0.564 ; p<0.01)$, and fixed math mindset was negatively correlated with math achievement $(r=-397 ; p<0.01)$. In other words, students who believed that math intelligence could be developed scored higher; however, students who believed that math intelligence could not be changed scored lower on the math achievement test.

Math mindsets showed similar correlations with academic grit as well. That is, students who endorsed a growth math mindset showed significantly more academic grit, and students who endorsed a fixed math mindset showed significantly less academic grit.

Table 3 shows the SEM results of the direct and indirect effects of math mindsets and academic grit on math achievement. Accordingly, growth math mindset did not have a significant direct effect on math achievement, but it showed a significant indirect effect mediated by academic grit $(\beta=0.393 ; p<0.01)$, which was moderate in size. The direct effect of fixed math mindset on math achievement was significant and negative $(\beta=-0.170 ; p<0.01)$ with a small effect size. The indirect effect of fixed math mindset on math achievement via academic grit was not significant.

The effect of academic grit on math achievement was also significant and positive $(\beta=0.662 ; p<0.01)$ with a moderate to high effect size. The final model explained the $36 \%$ of the variance in math achievement and $64 \%$ of the variance in academic grit.

The final model for the analyses is shown in Figure 2. Growth math mindset and fixed math mindset were both represented by three items, and academic grit was represented by 10 items. Fit indices were satisfactory, $\chi^{2}(114)=232.71, p<0.01, C F I=0.99, T L I=0.99, R M S E A=0.068$, and SRMR=0.026. The factor loadings of the 16 observed indicators of the relevant constructs were in the predicted directions, significant, and quite high. 
0.07

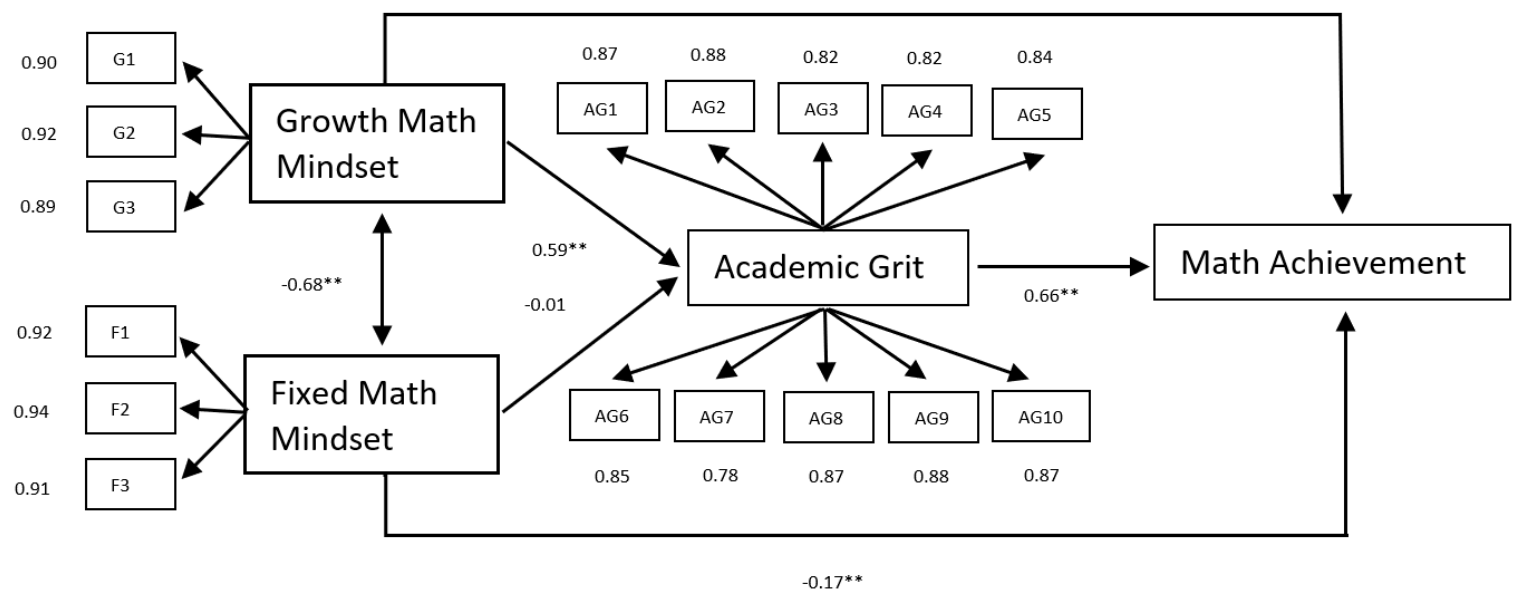

Figure 2. The final model of math mindsets, academic grit, and math achievement relationship $\left({ }^{* *} p<0.01\right)$

The association between growth and fixed math mindset was moderate to high and negative ( $\beta=-0.681$; $\mathrm{p}<0.01$ ) as expected.

\section{DISCUSSION}

This study focused on math mindsets, academic grit, and their relation to math achievement at the primary school level. Recent literature on self-theories recommends using domain-specific instruments to predict school achievement. We used the math mindsets scale similar to Dweck's (1999) original mindsets scale and the academic grit scale developed by Clark and Malecki (2019). Their relations with math achievement were examined through structural equation modeling with 225 primary school students. Results showed that there was not a direct effect of growth math mindset but a significant negative effect of fixed math mindset on math achievement. The indirect effect of growth math mindset on math achievement mediated by academic grit was positive and significant; the indirect effect of fixed math mindset was non-significant. The final model explained $36 \%$ of the variance in math achievement and $64 \%$ of academic grit. This means that more than one-third of the variance in primary math achievement was explained by math mindsets and academic grit. As Dweck (1999) and Duckworth (2016) emphasized self-theories can be critical in explaining individual differences in achievement. Follow-up studies could consider other self-theories, such as goal orientation and self-regulation in further explaining the individual differences in math achievement.

In their validation of the academic grit scale, Clark and Malecki (2019) found significant relations between academic grit and all of the outcome variables, including self-reported academic achievement, GPA, life satisfaction, and school satisfaction. However, they cautioned against self-reported measures of success. The current study utilized a valid and reliable measure of achievement and confirmed their findings. As Clark and Malecki (2019) as well as Credé et al. (2017) highlighted, grit is mostly studied with college-age groups and understudied in child samples. We tried to contribute to closing this gap by investigating grit in a primary school sample. As researchers indicated, domain-specific grit can be more ideal than general grit in explaining school-related outcomes (Clark \& Malecki, 2019; Schmidt et al., 2019). Both Clark and Malecki's (2019) and Schmidt et al.'s (2019) studies found that academic grit accounted for greater variance in academic achievement and GPA than did general grit. The current study showed that academic grit scale has potential in explaining math outcomes in child samples. We did not compare it with general grit but future studies can focus on this issue for child samples to further validate the scale. Longitudinal studies are also suggested as researchers indicate that academic grit may decline as students grow older (Clark \& Malecki, 2019).

As both Dweck (1999) and Duckworth (2016) stated, mindsets can affect the degree of effort and persistence one puts forward. In general, holding a growth mindset increases an individual's resilience, perseverance, and motivation towards learning. Previous research with different age groups showed that individuals who endorse a growth mindset show higher grit (Blackwell et al., 2007; Burgoyne et al., 2018; Kannangara et al., 2018; Zhao et al., 2018). In a similar vein, the current study found a positive effect of growth 
math mindset on academic grit. Future studies can investigate the effects of other self-theories on academic grit. Clark and Malecki (2019) stressed that there might be overlaps among self-beliefs, and further investigation is needed for the incremental validity of academic grit.

An important contribution of this study has been to show the mediating effect of academic grit between growth mindset and math achievement. It suggests that the reason a growth mindset can improve math achievement is that this mindset is able to enhance academic grit. Knowing about mindsets can change the way students see themselves and put forth more effort to succeed (Debacker et al., 2018; Paunesku et al., 2015; Rattan et al., 2015). Zhao et al. (2018) state that when students have a growth mindset they tend to become more self-directed and autonomous. They can pursue their interests in the face of temptations and this increases their overall grit. The growth mindset development can start in the family. When parents let children take their own academic decisions, solve their own problems and when they allow mistakes they create a growth mindset environment in the family. In terms of math, families can encourage their children to work harder in math and be supportive in solving math-related problems. School-family partnerships can focus on delivering students the message that through hard work, persistence, and practice, their math skills and intelligence can be improved; and, this notion is called a growth mindset. Once students acquire a growth math mindset, their academic grit will likely increase and it would be easier for them to reach their mathrelated academic goals.

Interventions that help develop domain-specific growth mindsets are recommended as early as primary school level. Previous intervention studies have been successful in helping students understand the brain plasticity and malleability of intelligence and developing a general growth mindset (Dweck, 2014). In these interventions, students were taught that the brain behaves like a muscle and it grows stronger with use. Every time they learn something new their brain forms new connections. Making a mistake is not always bad, in fact, it allows our brain to work harder. Students were also shown how to apply this information to their schoolwork. After the interventions both their achievement and motivation have improved. Interventions that also discourage students from viewing math intelligence as a fixed trait may help them overcome their fear of math and try harder (Hwang et al., 2019). When students are exposed to the messages such as 'some people are math geniuses', 'some people are born smart' or 'not everybody can be good at math', they can develop a fixed math mindset. Whereas, if successful people in math are presented as those who loved and devoted themselves to math, it conveys a growth math mindset (Dweck, 2014).

As well as students, teachers too need to be informed about the self-theories and math achievement relationship. Lou and Noels (2019) caution that "helping students to truly endorse growth mindsets is not just about telling them to keep trying" (p. 9). Rather, effective strategies are needed to encourage them to change their mindset (Dweck, 2006; Lou \& Noels, 2019). Knowing the fact that the brain makes new connections, especially when new and challenging tasks are introduced, might positively influence teaching. Classroom practices and school-based programs play an important role in shaping students' mindsets which in return affect their achievement. Teachers should strive to create inclusive classrooms where the understanding and progress of students are the main focus, and students can learn from their setbacks and mistakes (Dweck \& Yager, 2021; Murphy et al., 2021). They can start with creating collaborative classroom communities where students help each other to make sure nobody is left behind; at the same time, individual growth oriented feedback can be provided to show how much they have progressed. Using multiple and alternative assessments allows opportunities to revise and develop a growth mindset. It is crucial to create a classroom language where the teacher expresses a belief in every student's potential to learn. This will encourage students to try alternative strategies when they make mistakes (Murphy et al., 2021). When grading students, teachers can value effort as well as accuracy. Questioning students' efforts, such as the time they spent on preparing homework or the types of learning strategies they used can help them monitor their own learning (Stump et al., 2014). If students attribute their success to their effort they can become grittier on academic issues.

\section{Limitations}

The current study has some limitations. First, the sample came from a single primary school in Western Turkey. Therefore, the findings might not be transferrable to broader contexts. Second, the mechanisms of self-theories and math achievement relationships for subgroups were not explored. For example, as 
Bernardo's (2020) study, holding a growth mindset may not benefit students with low SES. Similarly, as in Hwang et al.'s (2019) analysis, holding a fixed mindset might affect achievement groups differently. Moreover, Credé et al.'s (2017) meta-analytical study indicated a few group-level differences in general grit. The same could be observed for academic grit. Future studies might therefore examine whether there are any group differences such as gender, SES, and age in the mechanisms of math mindset, academic grit, and math achievement relationships.

Finally, this study was conducted in Turkey, which is a Eurasian country influenced by both European and Asian cultures. In general, Turkish culture places high regard on school and especially math achievement. Therefore, the sizable effects of math mindset and academic grit on achievement could be due to cultural dispositions. Park et al. $(2018,2020)$ and Tang et al. (2019) reported modest positive effects of grit on adolescents' academic achievement in Finnish and US samples, respectively. Other researchers, however reported no associations between grit and achievement (Muenks et al., 2017; Steinmayr et al., 2018; Usher et al., 2018). Tang et al. (2019) claim that the effect of grit on achievement may depend on culture. Some cultures can be more likely to be accepting rather than resisting; thus, reflecting this into their schoolwork. Further studies on math mindset and academic grit in different cultures and cross-cultural comparisons are recommended.

\section{CONCLUSION}

The current study exhibited the positive effect of academic grit on math achievement and also, direct and indirect effects of math mindsets in a sample of primary school students. The findings of this study draw attention to domain-specific mindsets and academic grit, which are relatively understudied constructs in primary school settings. School-based mindset and academic grit interventions as well as inclusive classroom practices are advised. Although the current study provides evidence of significant associations among math mindsets, academic grit, and math achievement, further research is needed to explicate these associations in detail. For example, further research with subgroups in different domains and cultural settings could be helpful to strengthen the incremental validity of academic grit.

Author contributions: All authors were involved in concept, design, collection of data, interpretation, writing, and critically revising the article. All authors approve final version of the article.

Funding: The authors received no financial support for the research and/or authorship of this article.

Declaration of interest: Authors declare no competing interest.

Data availability: Data generated or analyzed during this study are available from the authors on request.

\section{REFERENCES}

Akos, P., \& Kretchmar, J. (2017). Investigating grit as a non-cognitive predictor of college success. The Review of Higher Education, 40(2), 163-186. https://doi.org/10.1353/rhe.2017.0000

Al-Mutawah, M. A., \& Fateel, M. J. (2018). Students' achievement in math and science: How grit and attitudes influence? International Education Studies, 11(2), 97-105. https://doi.org/10.5539/ies.v11n2p97

Bernardo, A. B. I. (2020). Socioeconomic status moderates the relationship between growth mindset and learning in mathematics and science: Evidence from PISA 2018 Philippine data. International Journal of School \& Educational Psychology, 9(2), 208-222. https://doi.org/10.1080/21683603.2020.1832635

Beyaztas, D. I., \& Hymer, B. (2018). An analysis of Turkish students' perception of intelligence from primary school to university. Gifted Education International, 34(1), 19-35. https://doi.org/10.1177/0261429416649041

Blackwell, L., Trzesniewski, K., \& Dweck, C. S. (2007). Implicit theories of intelligence predict achievement across an adolescent transition: A longitudinal study and an intervention. Child Development, 78(1), 246263. https://doi.org/10.1111/j.1467-8624.2007.00995.x

Bostwick, K. C. P., Collie, R. J., Martin, A. J., \& Durksen, T. L. (2017). Students' growth mindsets, goals, and academic outcomes in mathematics. Zeitschrift Fur Psychologie [Journal of Psychology], 225(2), 107-116. https://doi.org/10.1027/2151-2604/a000287 
Bostwick, K. C., Martin, A. J., Collie, R. J., \& Durksen, T. L. (2019). Growth orientation predicts gains in middle and high school students' mathematics outcomes over time. Contemporary Educational Psychology, 58, 213-227. https://doi.org/10.1016/j.cedpsych.2019.03.010

Bowman, N. A., Hill, P. L., Denson, N., \& Bronkema, R. (2015). Keep on truckin' or stay the course? Exploring grit dimensions as differential predictors of educational achievement, satisfaction, and intentions. Social Psychological and Personality Science, 6(6), 639-645. https://doi.org/10.1177/1948550615574300

Boyd, P., \& Ash, A. (2018). Mastery mathematics: Changing teacher beliefs around in-class grouping and mindset. Teaching and Teacher Education, 75, 214-223. https://doi.org/10.1016/j.tate.2018.06.016

Burgoyne, A. P., Hambrick, D. Z., Moser, J. S., \& Burt, S. A. (2018). Analysis of a mindset intervention. Journal of Research in Personality, 77, 21-30. https://doi.org/10.1016/j.jrp.2018.09.004

Byrne, B. M. (2016). Structural equation modelling with AMOS: Basic concepts, applications, and programming. Routledge. https://doi.org/10.4324/9781315757421

Clark, K. N., \& Malecki, C. K. (2019). Academic grit scale: Psychometric properties and associations with achievement and life satisfaction. Journal of School Psychology, 72, 49-66. https://doi.org/10.1016/j.jsp.2018.12.001

Claro, S., Paunesku, D., \& Dweck, C. S. (2016). Growth mindset tempers the effects of poverty on academic achievement. Proceedings of the National Academy of Sciences, 113(31), 8664-8668. https://doi.org/10.1073/pnas.1608207113

Cosgrove, J. M., Chen, Y. T., \& Castelli, D. M. (2018). Physical fitness, grit, school attendance, and academic performance among adolescents. BioMed Research International, 2018, 9801258. https://doi.org/10.1155/2018/9801258

Costa, A. \& Faria, L. (2018). Implicit theories of intelligence and academic achievement: A meta-analytic review. Frontiers in Psychology, 9, 829. https://doi.org/10.3389/fpsyg.2018.00829

Credé, M., Tynan, M. C., \& Harms, P. D. (2017). Much ado about grit: A meta-analytic synthesis of the grit literature. Journal of Personality and Social Psychology, 113(3), $492-511$. https://doi.org/10.1037/pspp0000102

Cury, F., Elliot, A. J., Da Fonseca, D., \& Moller, A. C. (2006). The social-cognitive model of achievement motivation and the $2 \times 2$ achievement goal framework. Journal of Personality and Social Psychology, 90(4), 666-679. https://doi.org/10.1037/0022-3514.90.4.666

Daly, I., Bourgaize, J., \& Vernitski, A. (2019). Mathematical mindsets increase student motivation: Evidence from the EEG. Trends in Neuroscience and Education, 15, 18-28. https://doi.org/10.1016/j.tine.2019.02.005

Datu, J. A. D., Valdez, J. P. M., \& King, R. B. (2016). Perseverance counts but consistency does not! Validating the short grit scale in a collectivist setting. Current Psychology, 35, 121-130. https://doi.org/10.1007/s12144-015-9374-2

DeBacker, T. K., Heddy, B. C., Kershen, J. L., Crowson, H. M., Looney, K., \& Goldman, J. A. (2018). Effects of a one-shot growth mindset intervention on beliefs about intelligence and achievement goals. Educational Psychology, 38(6), 711-733. https://doi.org/10.1080/01443410.2018.1426833

Degol, J. L., Wang, M. T., Zhang, Y., \& Allerton, J. (2018). Do growth mindsets in math benefit females? Identifying pathways between gender, mindset, and motivation. Journal of Youth and Adolescence, 47(5), 976-990. https://doi.org/10.1007/s10964-017-0739-8

Dixson, D. D., Worrell, F. C., Olszewski-Kubilius, P., \& Subotnik, R. F. (2016). Beyond perceived ability: The contribution of psychosocial factors to academic performance. Annals of the New York Academy of Sciences, 1377(1), 67-77. https://doi.org/10.1111/nyas.13210

Duckworth, A. (2016). Grit: The power of passion and perseverance. Scribner.

Duckworth, A. L., \& Quinn, P. D. (2009). Development and validation of the short grit scale (GRIT-S). Journal of Personality Assessment, 91(2), 166-174. https://doi.org/10.1080/00223890802634290

Duckworth, A. L., Peterson, C., Matthews, M. D., \& Kelly, D. R. (2007). Grit: Perseverance and passion for longterm goals. Journal of Personality and Social Psychology, 92(6), 1087-1101. https://doi.org/10.1037/00223514.92.6.1087

Dumfart, B., \& Neubauer, A. C. (2016). Conscientiousness is the most powerful non-cognitive predictor of school achievement in adolescents. Journal of Individual Differences, 37(1), 8-15. https://doi.org/10.1027/1614-0001/a000182

Dweck, C. S. (1999). Self-theories: Their role in motivation, personality and development. Taylor and Francis. 
Dweck, C. S. (2006). Mindset: The new psychology of success. Ballantine Books.

Dweck, C. S. (2014). Mindsets and math/science achievement. Carnegie Corporation.

Dweck, C. S., \& Yeager, D. (2021). Global mindset initiative introduction: Envisioning the future of growth mindset research in education. SSRN. https://doi.org/10.2139/ssrn.3911564

Dweck, C. S., \& Yeager, D. S. (2019). Mindsets: A view from two eras. Perspectives on Psychological Science, 14(3), 481-496. https://doi.org/10.1177/1745691618804166

Dweck, C. S., Chiu, C. Y., \& Hong, Y. Y. (1995). Implicit theories: Elaboration and extension of the model. Psychological Inquiry, 6(4), 322-333. https://doi.org/10.1207/s15327965pli0604_12

Fraenkel, J. R., \& Wallen, N. E. (2008). How to design and evaluate research in education. McGraw-Hill

Gouëdard, P. (2021). Can a growth mindset help disadvantaged students close the gap? OECD Publishing. https://doi.org/10.1787/20922f0d-en

Guerrero, L. R., Dudovitz, R., Chung, P. J., Dosanjh, K. K., \& Wong, M. D. (2016). Grit: A potential protective factor against substance use and other risk behaviors among Latino adolescents. Academic Pediatrics, 16(3), 275-281. https://doi.org/10.1016/j.acap.2015.12.016

Hair, J. F., Black, W. C., Babin, B. J., \& Anderson, R. E. (2014). Multivariate data analysis. Pearson.

Hwang, N., Reyes, M., \& Eccles, J. S. (2019). Who holds a fixed mindset and whom does it harm in mathematics? Youth \& Society, 51(2), 247-267. https://doi.org/10.1177/0044118X16670058

Kannangara, C. S., Allen, R. E., Waugh, G., Nahar, N., Khan, S. Z. N., Rogerson, S., \& Carson, J. (2018). All that glitters is not grit: Three studies of grit in university students. Frontiers in Psychology, 9, 1539. https://doi.org/10.3389/fpsyg.2018.01539

Kline, R. B. (2016). Methodology in the social sciences. principles and practice of structural equation modeling. Guilford Press.

Kyriazos, T. A. (2018). Applied psychometrics: Sample size and sample power considerations in factor analysis (EFA, CFA) and SEM in general. Psychology, 9(08), 2207-2230. https://doi.org/10.4236/psych.2018.98126

Lou, N. M., \& Noels, K. A. (2019). Promoting growth in foreign and second language education: A research agenda for mindsets in language learning and teaching. System, 86, 102-126. https://doi.org/10.1016/ j.system.2019.102126

Muenks, K., Wigfield, A., Yang, J. S., \& O'Neal, C. R. (2017). How true is grit? Assessing its relations to high school and college students' personality characteristics, self-regulation, engagement, and achievement. Journal of Educational Psychology, 109(5), 599-620. https://doi.org/10.1037/edu0000153

Müllensiefen, D., Harrison, P., Caprini, F., \& Fancourt, A. (2015). Investigating the importance of self-theories of intelligence and musicality for students' academic and musical achievement. Frontiers in Psychology, 6, 1702. https://doi.org/10.3389/fpsyg.2015.01702

Muller, C., \& Dweck, C.S. (1998). Praise for intelligence can undermine children's motivation and performance. Journal of Personality and Social Psychology, 75(1), 33-52. https://doi.org/10.1037/0022-3514.75.1.33

Mullis, I. V. S., \& Martin, M. O. (Eds.). (2017). TIMSS 2019 assessment frameworks. TIMSS \& PIRLS International Study Center. http://timssandpirls.bc.edu/timss2019/frameworks/

Murphy, M., Fryberg, S., Brady, L., Canning, E., \& Hecht, C. (2021). Global mindset initiative paper 1: Growth mindset cultures and teacher practices. SSRN. https://doi.org/10.2139/ssrn.3911594

Oriol, X., Miranda, R., Oyanedel, J. C., \& Torres, J. (2017). The role of self-control and grit in domains of school success in students of primary and secondary school. Frontiers in Psychology, 8, 1716. https://doi.org/10.3389/fpsyg.2017.01716

Park, D., Tsukayama, E., Yu, A., \& Duckworth, A. L. (2020). The development of grit and growth mindset during adolescence. Journal of Experimental Child Psychology, 198, 104889. https://doi.org/10.1016/j.jecp.2020.104889

Park, D., Yu, A., Baelen, R. N., Tsukayama, E., \& Duckworth, A. L. (2018). Fostering grit: Perceived school goalstructure predicts growth in grit and grades. Contemporary Educational Psychology, 55, 120-128. https://doi.org/10.1016/j.cedpsych.2018.09.007

Paunesku, D., Walton, G. M., Romero, C., Smith, E. N., Yeager, D. S., \& Dweck, C. S. (2015). Mindset interventions are a scalable treatment for academic underachievement. Psychological Science, 26(6), 784-793. https://doi.org/10.1177/0956797615571017 
Rattan, A., Savani, K., Chugh, D., \& Dweck, C. S. (2015). Leveraging mindsets to promote academic achievement: Policy recommendations. Perspectives on Psychological Science, 10(6), 721-726. https://doi.org/10.1177/1745691615599383

Romero, C., Master, A., Paunesku, D., Dweck, C. S., \& Gross, J. J. (2014). Academic and emotional functioning in middle school: The role of implicit theories. Emotion, 14(2), 227-234. https://doi.org/10.1037/a0035490

Ryan, S., \& Mercer, S. (2012). Language learning mindsets across cultural settings: English learners in Austria and Japan. OnCUE Journal, 6(1), 6-22.

Schmidt, F. T. C., Fleckenstein, J., Retelsdorf, J., Eskreis-Winkler, L., \& Möller, J. (2019). Measuring grit. European Journal of Psychological Assessment, 35(3), 436-447. https://doi.org/10.1027/1015-5759/a000407

Sigmundsson, H., Haga, M., \& Hermundsdottir, F. (2020). Passion, grit and mindset in young adults: Exploring the relationship and gender differences. New Ideas in Psychology, 59, 100795. https://doi.org/10.1016/j.newideapsych.2020.100795

Sisk, V. F., Burgoyne, A. P., Sun, J., Butler, J. L., \& Macnamara, B. N. (2018). To what extent and under which circumstances are growth mindsets important to academic achievement? Two meta-analyses. Psychological Science, 29(4), 549-571. https://doi.org/10.1177/0956797617739704

Steinmayr, R., Weidinger, A. F., \& Wigfield, A. (2018). Does students' grit predict their school achievement above and beyond their personality, motivation, and engagement? Contemporary Educational Psychology, 53, 106-122. https://doi.org/10.1016/j.cedpsych.2018.02.004

Strayhorn, T. L. (2014). What role does grit play in the academic success of black male collegians at predominantly white institutions? Journal of African American Studies, 18, 1-10. https://doi.org/10.1007/s12111-012-9243-0

Stump, G. S., Husman, J., \& Corby, M. (2014). Engineering students' intelligence beliefs and learning. Journal of Engineering Education, 103(3), 369-387. https://doi.org/10.1002/jee.20051

Tabachnick, B. G., \& Fidell, L. S. (2007). Using multivariate statistics. Allyn and Bacon.

Tang, X., Wang, M. T., Guo, J., \& Salmela-Aro, K. (2019). Building grit: The longitudinal pathways between mindset, commitment, grit, and academic outcomes. Journal of Youth and Adolescence, 48(5), 850-863. https://doi.org/10.1007/s10964-019-00998-0

Tucker-Drob, E. M., Briley, D. A., Engelhardt, L. E., Mann, F. D., \& Harden, K. P. (2016). Genetically-mediated associations between measures of childhood character and academic achievement. Journal of Personality and Social Psychology, 111(5), 790-815. https://doi.org/10.1037/pspp0000098

Usher, E. L., Li, C. R., Butz, A. R., \& Rojas, J. P. (2018). Perseverant grit and self-efficacy: Are both essential for children's academic success? Journal of Educational Psychology, 111(5), 877-902. https://doi.org/10.1037/edu0000324

West, M. R., Kraft, M. A., Finn, A. S., Martin, R. E., Duckworth, A. L., Gabrieli, C. F., \& Gabrieli, J. D. (2016). Promise and paradox: Measuring students' non-cognitive skills and the impact of schooling. Educational Evaluation and Policy Analysis, 38(1), 148-170. https://doi.org/10.3102/0162373715597298

Wolters, C. A., \& Hussain, M. (2015). Investigating grit and its relations with college students' self-regulated learning and academic achievement. Metacognition and Learning, 10, 293-311. https://doi.org/10.1007/s11409-014-9128-9

Yuksel, D., Curle, S., \& Kaya, S. (2021). What role do language learning mindsets play in English Medium Instruction? A comparison of engineering and business administration in Turkey. Journal for the Psychology of Language Learning, 3(1), 50-62. https://doi.org/10.1016/j.system.2021.102651

Zhao, Y., Niu, G., Hou, H., Zeng, G., Xu, L., Peng, K., \& Yu, F. (2018). From growth mindset to grit in Chinese schools: The mediating roles of learning motivations. Frontiers in Psychology, 9, 2007. https://doi.org/10.3389/fpsyg.2018.02007

Zhao, J., \& Wang, M. (2014). Mothers' academic involvement and children's achievement: Children's theory of intelligence as a mediator. Learning and Individual Differences, 35, 130-136. https://doi.org/10.1016/j.lindif.2014.06.006

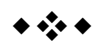

